\title{
REFERENCE
}

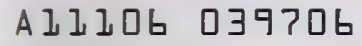

NIST

\section{NBSIR 77-1237}

\section{PUBLICATIONS}

\section{Transpiration Heat Transfer in Thermal Energy Storage Devices}

B. A. Peavy and W. E. Dressler

Thermal Engineering Section Center for Building Technology Institute for Applied Technology National Bureau of Standards

Washington, D.C. 20234

May 1977

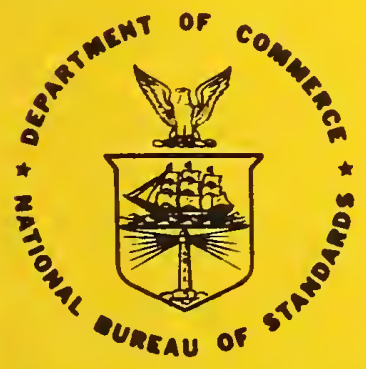

U. S. DEPARTMENT OF COMMERCE NATIONAL BUREAU OF STANDARDS

QC

100

456 



\section{TRANSPIRATION HEAT TRANSFER IN} THERMAL ENERGY STORAGE DEVICES

B. A. Peavy and W. E. Dressler

Thermal Engineering Section Center for Building Technology Institute for Applied Technology National Bureau of Standards

Washington, D.C. 20234

May 1977

U.S. DEPARTMENT OF COMMERCE, Juanita M. Kreps, Secretary

Dr. Sidney Harman, Under Secretary

Jordan J. Baruch, Assistant Secretary for Science and Technology NATIONAL BUREAU OF STANDARDS, Ernest Ambler, Acting Director 



\section{TRANSPIRATION HEAT TRANSFER \\ IN THERMAL ENERGY \\ STORAGE DEVICES}

by

B. A. Peavy and W. E. Dressler

\section{ABSTRACT}

The storage of thermal energy at a suitable temperature level from sources such as solar energy or waste heat processes can make that energy available for space heating at a later time period. This report is concerned with sensible heat transfer that takes place in a thermal storage device composed of a porous material with a fluid (water) transpiring through it. Experiments were performed on a prototype thermal storage device and the results were compared to numerical values computed from an analytical model. The comparison is shown to be very good. Further experimentation is considered necessary in order to more fully examine the effects of stratified and mixing-type flows, heat losses, conduction heat flow in the heat storage container, and unsteady initial conditions.

Keywords: Porous media; thermal energy storage; transpiration heat transfer. 
TRANSPIRATION HEAT TRANSFER

IN THERMAL ENERGY STORAGE DEVICES

by

B. A. Peavy and W. E. Dressler

\section{Contents}

Page

Introduction

1

Test Apparatus

2

Testing Procedure

3

Analytical Model

4

Discussion of Results

10

Acknowledgments

14

List of Figures 


\section{TRANSPIRATION HEAT TRANSFER \\ IN THERMAL ENERGY \\ STORAGE DEVICES}

by

B. A. Peavy and W. E. Dressler

\section{INTRODUCTION}

With the growing emphasis on the utilization of solar energy for space heating in buildings, focus is drawn to the requirements for storage of the energy at a suitable temperature level for use at time periods when solar energy is not available, such as at night or on cloudy days when the heat is most often needed. Consideration is also being given to long-term storage of thermal energy whereby energy is collected during the summer months for utilization during the winter season

Generally, thermal storage may be classified in two ways; namely, sensible heat and latent heat storage (change of phase of a material). This report is concerned with the sensible heat changes that take place in a porous material with a fluid (water) transpiring through it. An example of such a storage device is a bed of sand with water seeping through it. In the daytime, the water flows through a solar collector array where it absorbs the thermal energy and transfers it into the bed of sand through which the water passes. At night, the water passes through the storage bed where it is heated and then flows through one or more heat exchangers where it transfers the energy to the building for domestic water heating or space heating. The water returns to the sand bed to pick up additional heat and the process is repeated. 
There has been relatively little work done on the testing of sensible heat storage devices during typical transient operating condition and there is a need for the development of methods for determining the effectiveness of these devices.*. This paper deals with the development of an analytical model for predicting the performance of sensible thermal energy storage units and the comparison of calculated results to actual experimental results. With the use of the model, the prediction of the thermal performance of transpiration energy storage units should permit a better understanding of the phenomena involved. TEST APPARATUS

The general testing approach used was to subject a porous bed of sand with water flowing through it at a uniform temperature (the bed and fluid were initially at steady conditions) to a sudden change in entering fluid temperature. The transient temperature distribution was then determined until steady conditions were again approached. This is the technique recently adopted by the heating and air conditioning industry for testing thermal storage devices.*.

The experimental apparatus, as shown schematically in figure 1, consisted of a 4-in. (10.2 cm) inside-diameter plastic cylinder with a $1 / 4-$ in. $(0.64 \mathrm{~cm})$ wall. The first $24 \mathrm{in.}(61 \mathrm{~cm})$ of the cylinder were fitted every 2 in. $(5.1 \mathrm{~cm})$ with thermocouples which were located at the center of the cylinder. The cylinder was wrapped with a $1-i n .(2.5 \mathrm{~cm})$ thickness of rigid glass-fiber insulation for the first three tests described in the next section. An additional 1 in. $(2.5 \mathrm{~cm})$ was added for the fourth

* Method of Testing Thermal Storage Devices Based on Thermal Performance. ASHRAE Standard 94-77, February, 1977. 
and final test. Provision was made for introducing either hot or cold water from the building supply at the top of the cylinder by appropriate valving. This technique was used for the first three tests. Additional steps were taken for the fourth test to control the temperature of the entering fluid to within $\pm 0.5 \mathrm{~F}( \pm 0.3 \mathrm{C})$. The porous matrix material, Ottawa sand, had a density of $109 \mathrm{lbs} / \mathrm{ft}^{3}\left(1746 \mathrm{~kg} / \mathrm{m}^{3}\right)$ and occupied 66 percent of the volume of the cylinder.

TESTING PROCEDURE

To begin the experiment, a first test was run by passing hot water through an empty cylinder at approximately $117 F(47.2 \mathrm{C})$ at a flow rate of $0.4 \mathrm{gal} / \mathrm{h}\left(4.2 \times 10^{-7} \mathrm{~m}^{3} / \mathrm{s}\right)$. The hot water was then suddenly stopped and cold water at $74 \mathrm{~F}(23.3 \mathrm{C})$ was introduced. The temperature distributions were recorded over intervals of time. A graph of the results is shown in figure 2.

The next step in the testing procedure was to fill the cylinder to a height of $24 \mathrm{in.}(61 \mathrm{~cm})$, with a 20 - to 30 -mesh silica sand from ottawa, Illinois. Two more tests were then run by saturating the sand matrix with hot water at flow rates of $0.29\left(3.0 \times 10^{-7}\right)$ and $0.55\left(5.8 \times 10^{-7}\right)$ gal $/ \mathrm{h},\left(\mathrm{m}^{3} / \mathrm{s}\right)$ respectively. The hot water was suddenly stopped and cold water was introduced at the same respective flow rates and temperature distributions once again recorded at intervals of time. Graphical representations of these two tests are shown in figures 3 and 4 , respectively. Upon close examination of the results of the last two tests, questions arose concerning the lack of a constant initial matrix temperature, the failure to get as highly stratified conditions as had been expected 
due to the buoyant effects of placing cold water on top of hot water, the effects of radial heat losses on the system, and the possible conductance of energy along the cylinder walls providing a by-passing of the porous matrix. Therefore, a number of changes in the system were initiated. First, constant temperature hot water and chilled water sources were used to sufficiently reduce temperature fluctuations during the experiments. Secondly, it was decided to first cool the matrix and then introduce hot water to prevent hot and cold water mixing due to buoyancy. A second inch $(2.5 \mathrm{~cm})$ of glass fiber insulation was added to the exterior of the cylinder to reduce radial heat transfer. Initial and final matrix temperatures were chosen to be above and below room air temperatures, respectively, to minimize radial heat transfer due to temperature differences between cylinder and ambient air. Finally, thermocouples were added to the inside and outside of the cylinder wall to check for possible lateral conductance of heat past the porous matrix material. (No evidence was found in the subsequent experiment to support such concern.)

A final test was made. The total matrix of silica sand and water was initially cooled to a temperature of $54 \mathrm{~F}$ (12.2C) with a flow rate of $0.3 \mathrm{gal} / \mathrm{h}\left(3.2 \times 10^{-7} \mathrm{~m}^{3} / \mathrm{s}\right.$. The chilled water was suddenly stopped and hot water at 106F (41.1C) was introduced, while recording temperatures at time intervals until a steady-state condition was reached. The graph of temperature versus time is shown in figure 5. ANALYTICAL MODEL

The following assumptions were made in formulating the analytical model: 
1. Thermal, physical, and transport properties are constant.

2. Heat conduction in the porous matrix and fluid flow through the interstices are one-dimensional in a direction normal to the bounding surfaces.

3. The temperature of the fluid and solid are assumed to be equal in any matrix element normal to the fluid flow, and the matrix thermal properties are treated as effective values. The thermal conductivity includes heat transfer through both the fluid and solid components of the matrix. In a similar manner, the volumetric specific heat of a flooded (saturated) matrix is a sum of proportional values of both components.

4. The specific heat of the flowing fluid is a definable property of the fluid as distinct from that of the matrix materials, which form a fixed volume.

With these assumptions, a heat balance was performed on the solid material of an elemental slice of the porous matrix, figure 6 . For the transient one-dimensional transpiration heat-transfer problem of a fluid through a porous matrix, the following governing partial differential equation was derived:

$$
\frac{\partial^{2} v}{\partial x^{2}}-2 \beta \frac{\partial v}{\partial x}-\frac{e^{2}}{\alpha_{m}} \frac{\partial v}{\partial t}=0
$$

where $\mathrm{v}=$ temperature potential

$x=$ ratio of the distance in the solid to the length, \&

$\ell=$ length of fluid flow path through storage unit

$\alpha_{m}=$ thermal diffusivity of the storage unit 


$$
t=t i m e
$$

$2 \beta=$ the product of the mass flux of the fluid, $G$, the fluid specific heat, $c$, and the length, $\ell$, divided by the thermal conductivity, $\lambda_{m}$ of the storage unit, $\frac{\text { Gcl }}{\lambda_{m}}$

The general solution of (I) is given by:

$$
v=A_{0}+B_{0} e^{2 \beta x}+e^{\beta x-\beta^{2}} \gamma\left[A_{n} \cos \delta_{n} x+B_{n} \sin \delta_{n} x\right] e^{-\delta_{n}^{2} \gamma}
$$

where $r=\alpha t / \ell^{2}$, and constants $A$ and $B$ satisfy initial and boundary conditions. Two of the three required boundary conditions are (I) an initial temperature potential, $v=0$ in the region $0 \leq x \leq 1$, and (2) for time greater than zero, the heat flux is zero at $x=1$. The following paragraphs describe alternate solutions of equation (I) depending on the third boundary condition chosen.

Solution No. I

For a time greater than zero, the temperature at the matrix entry face, $x=0$, is assumed to be suddenly raised and maintained at a value $v=V$. The solution to equation (I) then becomes:

$$
\frac{v}{v}=1-2 e^{\beta x-\beta^{2} \gamma}\left[\frac{\delta_{n} \sin \delta_{n} x e^{-\delta_{n}^{2} \gamma}}{\delta_{n}^{2}+\beta^{2}+\beta}\right.
$$

where $\delta_{n}$ are positive roots of

$$
\beta \sin \delta+\delta \cos \delta=0 \text {. }
$$

\section{Solution No. 2}

For times greater than zero, the fluid-entry temperature at $\mathbf{x}=0$ can more accurately be assumed to be

$$
v=V\left(1-e^{-\Psi t}\right)
$$


where $\Psi$ is an independent damping factor to be determined experimentally for a given transpiration configuration. The solution to equation (1) then becomes:

$$
\frac{v}{v}=1-F(x) e^{\beta x-\Psi t}+2 e^{\beta x-\beta^{2} \gamma}\left[\frac{\delta_{n} \sin \delta_{n} x e^{-\delta_{n}^{2} \gamma}}{\left[\left(\beta^{2}+\delta_{n}\right) / \sigma-1\right]\left(\delta_{n}^{2}+\beta^{2}+B\right)}\right.
$$

for:

$$
\begin{array}{ll}
F(x)=\frac{\beta \sinh \phi(1-x)+\phi \cosh \phi(1-x)}{\beta \sinh \phi+\phi \cosh \phi} & \text { for } \beta^{2}>\sigma \\
F(x)=\frac{\beta \sin \phi(1-x)+\phi \cos \phi(1-x)}{\beta \sin \phi+\phi \cos \phi} & \text { for } \beta^{2}<\sigma \\
F(x)=\frac{\beta(1-x)+1}{\beta+1} & \text { for } \beta^{2}=\sigma \\
\text { and } \sigma=\Psi \ell^{2} / \alpha, \phi^{2}=\left|\beta^{2}-\sigma\right| . &
\end{array}
$$

As a result of the experimental physical constraints, equation (5) more closely approximates the actual fluid-entry temperature in a transpirational heat storage device than does the assumption of a step change in the fluid temperature.

Solution No. 3

Additional experimental constraints most often require the inclusion of heat loss or gain radially to the surrounding ambient air temperature. Consequently the more general governing partial differential equation allowing for two-dimensional heat transfer within the matrix is given by: 


$$
\ell^{2}\left(\frac{\partial^{2} v}{\partial r^{2}}+\frac{1}{r} \frac{\partial v}{\partial r}\right)+\frac{\partial^{2} v}{\partial x^{2}}-2 \beta \frac{\partial v}{\partial x}-\frac{\ell^{2}}{\alpha} \frac{\partial v}{\partial t}=0
$$

No radial fluid flow is assumed and the following boundary conditions are assumed:

$$
\begin{array}{rlrl}
\text { at } \mathrm{x} & =0 & \mathrm{v} & =\mathrm{V}\left(1-\mathrm{e}^{-\Psi \mathrm{t}}\right) \\
& \text { at } \mathrm{x}=1 & \mathrm{dv} / \mathrm{dx}=0 \\
\text { at } \mathrm{r}=\mathrm{a} & -\lambda_{\mathrm{m}} \mathrm{dv} / \mathrm{dr}=\mathrm{H}(\mathrm{v}-\mathrm{U}),-\mathrm{a} \frac{\mathrm{dv}}{\mathrm{dr}}=\mathrm{h}(\mathrm{v}-\mathrm{U})
\end{array}
$$

where $U$ is the temperature potential of the surrounding ambient and $h=a H / \lambda_{m}$, dimensionless, and $a$ is the inside radius of the storage unit. The solution to equation (7) using the foregoing boundary conditions is given by:

$$
\frac{v}{V}=2 h e^{B x}\left(A_{1}+A_{2}+A_{3}+A_{4}\right)
$$

where:

$$
\begin{aligned}
& A_{1}=\sum \frac{J_{0}\left(y_{n} r / a\right)}{\left(y_{n}^{2}+h^{2}\right) J_{0}\left(y_{n}\right)}=\frac{\beta \sinh \Omega_{n}(1-x)+\Omega_{n} \cosh \Omega_{n}(1-x)}{\beta \sinh \Omega_{n}+\Omega_{n} \cosh \Omega_{n}} \\
& A_{2}=\frac{U}{V} \sum \frac{\delta_{n} \sin \delta_{n} x}{\delta_{n}^{2}+\beta^{2}+\beta} \cdot \frac{I_{0}\left(\phi_{n} r / a\right)}{\beta I_{0}\left(\phi_{n}\right)+\phi_{n} I_{1}\left(\phi_{n}\right)} \\
& A_{3}=-e^{-\Psi t} \sum \frac{J_{0}\left(y_{n} r / a\right) F_{n}(x)}{\left(y_{n}^{2}+h^{2}\right) J_{0}\left(y_{n}\right)}
\end{aligned}
$$




$$
A_{4}=2 e^{-\beta^{2} \gamma} \sum_{n}^{J_{0}\left(y_{n} r / a\right) e^{-\frac{y_{n}{ }^{2} l^{2} \gamma}{a^{2}}}} \sum_{\frac{1}{\left(y_{n}{ }^{2}+h^{2}\right) J_{0}\left(y_{n}\right)}}^{z_{m} n} \frac{\delta_{m} s i n \delta_{m} x e^{-\delta_{m}{ }^{2} \gamma}}{\left(\delta_{m}{ }^{2}+\frac{y_{m}{ }^{2} l^{2}}{a^{2}}+\beta^{2}\right)\left(\delta_{m}{ }^{2}+\beta^{2}+\beta\right)}
$$

and where:

$$
\begin{aligned}
& y_{n} \text { are roots of } y_{1}(y)-h J_{0}(y)=0 \\
& \delta_{n} \text { are roots of } \beta \sin \delta+\delta \cos \delta=0 \\
& \Omega_{n}^{2}=\left(\beta^{2}+\delta_{n}^{2}\right) a^{2} / l^{2} \\
& Z_{m, n}=\frac{\delta_{m}^{2}+\beta^{2}}{\left.\delta_{m}^{2}+y_{n}{ }^{2} l^{2} / a^{2}+\beta^{2}\right) / \sigma-1}-\frac{U}{V} y_{n}^{2} \ell^{2} / a^{2} \\
& F_{n}(x)=\frac{\beta \sinh \phi_{n}(1-x)+\phi_{n} \cosh \phi_{n}(1-x)}{\beta \sin \phi_{n}+\phi_{n} \cosh \phi_{n}} \text { for } \beta^{2}+\frac{y_{n}{ }^{2} l^{2}}{a^{2}}>\sigma
\end{aligned}
$$$$
F_{n}(x)=\frac{\beta \sin \phi_{n}(1-x)+\phi_{n} \cos \phi_{n}(1-x)}{\beta \sin \phi_{n}+\phi_{n} \cos \phi_{n}} \quad \text { for } \beta^{2}+\frac{y^{2} \ell^{2}}{a^{2}}<\sigma
$$$$
F_{n}(x)=\frac{\beta(1-x)+1}{\beta+1} \quad \text { for } \beta^{2}+\frac{y^{2} \ell^{2}}{a^{2}}=\sigma
$$

$$
\sigma=\frac{\Psi \ell^{2}}{\alpha}, \phi_{\mathrm{n}}^{2}=\left|\beta^{2}+\frac{\mathrm{y}_{\mathrm{n}}^{2} \ell^{2}}{\mathrm{a}^{2}}-\sigma\right|
$$

and $J(z), J(z), I d z)$ and $I(z)$ are Bessel functions. 
For computing numerical solutions of equations (3), (6) or (11), particular care must be taken for large values of the dimensionless parameter, $\beta$. At $x=1$, the fluid exit from the thermal energy storage device, the exponential factor can become very large, and the summation term must be correspondingly very small such that $\mathrm{v} / \mathrm{V}$ lies between zero and unity. It is therefore suggested that computer calculations be performed in the double-precision mode to avoid excessive loss of significance in the summation of terms. For $\beta$ greater than 30 , it may become necessary to employ some type of extended precision routines to avoid spurious results, depending upon the magnitude of $\beta-\beta^{2} \gamma$.

\section{DISCUSSION OF RESULTS}

Figure 2 shows the temperature history of the experimental unit filled only with water initially held at a high temperature and where cold water was introduced at the top of the unit. Due to the reduced buoyancy of the cold water almost perfect mixing existed as is evident from the figure. At a given time, the temperature at the exit-face (bottom) is not much different from that at the fluid entry-face (top). The reverse test of suddenly introducing hot water to the cylinder initially filled with cold water was not performed; however, intuitively one would expect stratification of the warmer layers near the top whereby the temperature at the fluid exit-face would remain at its initial temperature for a definite time period. At the flow rate of $0.4 \mathrm{gal} / \mathrm{h}\left(4.2 \times 10^{-7}\right.$ $\mathrm{m}^{3} / \mathrm{s}$ ), it would be expected that the water temperature leaving the unit would be the same as the entering water temperature at the end of 3.2 hours. Figure 2 shows this to be true at the end of 1.6 hours and is an indication of the heat loss that occurred from the unit to the ambient. 
In order to compare the results of the analytical model to the experimental results, it is necessary to determine the thermal properties of the thermal storage device. The solid portion of the matrix material is a natural silica sand from Ottawa, Illinois, with a standard mesh size of 20 to 30. The measured dry density was $1091 \mathrm{bs} / \mathrm{ft}^{3}\left(1746 \mathrm{~kg} / \mathrm{m}^{3}\right)$ and the specific heat was estimated to be $0.185 \mathrm{Btu} / \mathrm{Ib} \cdot \mathrm{F} \quad(775 \mathrm{~J} / \mathrm{kg} \cdot \mathrm{C})$ at about $85 \mathrm{~F}$ (29C) from various literature sources. The volumetric porosity was 34 percent. When saturated with water, the water was 16.2 percent by weight. From these data, the density and specific heat for the thermal storage device, including container, were about $146.7 \mathrm{Ib} / \mathrm{ft}^{3}$ $\left(2350 \mathrm{~kg} / \mathrm{m}^{3}\right)$ and $\left.0.32 \mathrm{Btu} /(\mathrm{Ib} \cdot \mathrm{F})(1340 \mathrm{~J} / \mathrm{kg} \cdot \mathrm{C})\right)$ respectively. From Woodside and Messmer, * the thermal conductivity of the storage device for a porosity of 34 percent is given as $1.94 \mathrm{Btu} /(\mathrm{h} \cdot \mathrm{ft} \cdot \mathrm{F})(3.36 \mathrm{~W} / \mathrm{m} \cdot \mathrm{C}))$, and the thermal diffusivity $.0413 \mathrm{ft}^{2} / \mathrm{h}\left(1.07 \times 10^{-7} \mathrm{~m}^{2} / \mathrm{s}\right)$. For the last three tests with water flow rates of $0.29,0.55$ and $0.30\left(3.0 \times 10^{-7}\right.$, $5.8 \times 10^{-7}$, and $\left.3.2 \times 10^{-7} \mathrm{~m}^{3} / \mathrm{s}\right)$ the values of $\beta=\mathrm{Gcl} / 2 \lambda_{\mathrm{m}}$ were 14.31 , 27.13 , and 14.80, respectively.

For the Biot number, $h=a H / \lambda m$, values were determined from the relationship:

$$
\frac{1}{\mathrm{aH}}=\frac{\ln \left(r_{1} / \mathrm{a}\right)}{\mathrm{K}_{1}}+\frac{\ln \left(\mathrm{r}_{2} / \mathrm{r}_{1}\right)}{\mathrm{K}_{2}}+\frac{1}{r_{2} \mathrm{H}_{0}}
$$

* Woodside and Messmer, "Thermal Conductivity of Porous Media, Unconsolidated Solids," Journal of Applied Physics, (32), 1961, p. 1688. 
where

$$
\begin{aligned}
\mathrm{K}_{1}= & \text { thermal conductivity of container, } 0.083 \mathrm{Btu} /(\mathrm{h} \cdot \mathrm{ft} \cdot \mathrm{F}) \\
& (1.4 \mathrm{~W} /(\mathrm{m} \cdot \mathrm{C}) \\
\mathrm{K}_{2}= & \text { thermal conductivity of insulation, } 0.021 \mathrm{Btu} /(\mathrm{h} \cdot \mathrm{ft} \cdot \mathrm{F}) \\
& (.36 \mathrm{~W} /(\mathrm{m} \cdot \mathrm{C}) \\
\mathrm{a}= & \text { inside radius of container, } 2.0 \mathrm{in}(5.1 \mathrm{~cm}) \\
r_{1}= & \text { outside radius of container, } 2.3 \mathrm{in}(5.7 \mathrm{~cm}) \\
r_{2}= & \text { outside radius of insulation, } 3.3 \mathrm{in} \mathrm{or} 4.3 \mathrm{in}(8.3 \mathrm{or} 10.8 \mathrm{~cm}) \\
H_{0}= & \text { coefficient of heat transfer at } \mathrm{r}_{2}, 1.08 \mathrm{Btu} /\left(\mathrm{h} \cdot \mathrm{ft}^{2} \cdot \mathrm{F}\right)
\end{aligned}
$$

For tests 2 and $3, h=.0233$ (with $l$ in. $(2.5 \mathrm{~cm}$ ) of insulation) and for test $4, h=0.015$ (with 2 in. $(5.1 \mathrm{~cm}$ ) of insulation). For tests 2 , 3 and 4 the damping factors, $\Psi$, were determined experimentally to be $3.48,5.59$ and 12, respectively.

The temperature potential, $v$, is defined by the relationship:

$$
\frac{v_{x}}{V}=\frac{T_{x}-T_{i}}{T_{e}-T_{i}}
$$

where $\mathrm{T}_{\mathrm{x}}$ is the temperature at a position $\mathrm{x}, \mathrm{T}_{i}$ is the initial temperature, and $\mathrm{T}_{\mathrm{e}}$ is the water temperature entering the storage device, such that

$$
\frac{v_{0}}{V}=1-e^{-\Psi t} .
$$

For tests 2 and 3 , the entering water temperature was essentially the same as the air temperature surrounding the storage device; therefore, U of equation (10) is unity. For test 4, 


$$
\frac{U}{V}=(78.9-54.0) /(106-54)=.479
$$

Given the above information, numerical results for the analytical model, equation (11), are shown in figures 7 and 8 and compared with the experimental results for the temperature potential, $v$, at the exit of the storage device. Except for the initial temperature rise at the fluid exit for tests 2 and 3, the agreement between the analytical model and the experimental results can be considered very good.

The prototype storage unit used for the tests described herein was small and presented problems that are to be corrected in future testing. A new storage unit is presently being constructed which will be larger and contain additional instrumentation necessary for accurately determining heat loss from the unit. However, the data obtained does allow some general conclusions to be made concerning the effectiveness of thermal energy storage in a sand bed. Figure 9 shows a plot of $1-\frac{V_{1}}{V}$ for the results of test 4 as a function of a dimensionless time defined by :

$$
\frac{\dot{m} C\left(T_{e}-T_{i}\right)}{S C} t
$$

where

$$
\begin{aligned}
\dot{\mathrm{m}}= & \text { mass flow rate of the fluid } \\
\mathrm{SC}= & \text { the storage capacity of the thermal storage unit } \\
& \text { which has its temperature increased from } \mathrm{T}_{i} \text { to } \mathrm{T}_{e}
\end{aligned}
$$

In addition, figure 9 also includes calculated results for two water tanks of the same volume having the same flow rate through them as did 
the sand bed of test 4. In one case, the water tank is assumed to be completely stratified and in the second, completely mixed. In both cases, zero heat loss was assumed from the tanks.

The area under each curve of figure 9 is directly proportional to the amount of energy that was stored in the device. In order to compare the performance of the three units, it is convenient to choose the time period 0 to 1 (dimensionless time). This is consistent with the procedure currently being considered by ASHRAE for testing and rating storage devices that was mentioned previously. Based upon the curves in figure 9, a perfectly mixed water tank is only 63 percent as effective in storing thermal energy during this transient period as the completely stratified tank (which of course is never obtained in actual practice). However, the sand bed remains rather highly stratified at the chosen flow rate and as a result is within 88 percent as effective as the ideal case.

\section{CONCLUSION}

This paper is a preliminary report to ongoing work in the development of methods for determining the effectiveness of thermal storage devices, and it must be recognized that certain conclusions must be reserved until the completion of the ongoing work.

Certainly, heat loss from a thermal storage device can be considered a serious matter, especially when heat loss occurs at a time when there is no need for heating and the heat is unavailable when it is needed. Figure 8 gives an indication of the heat loss upon addition of heat to a device whereby the exit temperature rise attained only about 91 percent of the entry temperature rise. A heated storage unit allowed to 
stand for several hours would lose considerable heat under these conditions .

The analytical model, using thermal properties from the literature, gives very good agreement to actual experimental results on a thermal storage device employing the transpiration process. Solution number 3 , although a seemingly cumbersome set of equations, gives numerical solutions in a very fast manner when programmed for the computer and accounts for radial and actual heat flows as well as fluid flow. With this model it is possible to predict the thermal performance of transpiration energy storage units.

One test was performed using water only (without sand) in the storage unit, and the results are given in figure 2. This test involves the introduction of cold water on top of an initially uniform hot water. There was an almost perfect mixing due to the higher density of the cold water seeking a lower level and thereby a mixing with the hot water. Perfect mixing is not a desirable feature for thermal storage units in that the exit temperature should be maintained as close as possible to the initial temperature at the beginning of heating or cooling cycle. For the case cited above, the introduction of cold water at the bottom of the storage unit would promote stratification, but involves additional piping and controls to give stratification for both the heating and cooling cycles of the thermal storage unit.

Figure 3 shows the introduction of cold water on top of a heated sand-water combination where the exit water temperature is maintained at a higher level for a considerably longer period of time. The use of a sand bed may preclude the necessity of extra piping and controls and the 
reversal of fluid flow that is necessary for the heating and cooling cycles of water thermal storage devices.

\section{ACKNOWLEDGMENT}

The authors wish to express appreciation to Mr. Walter Ellis for installation of the apparatus and instrumentation and the day-to-day operation of the experiments. 
1. Schematic of Prototype Thermal Storage Unit.

2. Temperature History of Thermal Storage Unit Initially Filled with Water at $177 \mathrm{~F}$. At Time Equal Zero, Water at $74 \mathrm{~F}$ and a Flow Rate of $0.4 \mathrm{gal} / \mathrm{h}$ was Introduced at Top of Unit.

3. Temperature History of Thermal Storage Unit Filled with a Silica Sand-Water Mixture Initially at 116F. At Time EQual Zero Water at $74 \mathrm{~F}$ and a Flow Rate of $0.29 \mathrm{gal} / \mathrm{h}$ was Introduced.

4. Temperature History for Thermal Storage Unit of Figure 3, except Flow Rate was $0.55 \mathrm{gal} / \mathrm{h}$.

5. Temperature History of Thermal Storage Unit Initially at 54F. At Time Equal Zero Water at $106 \mathrm{~F}$ and a Flow Rate of $0.3 \mathrm{gal} / \mathrm{h}$ was Introduced.

6. Transpiration Heat Flow Through Elemental Slice of Thermal Storage Unit.

7. History of Temperature Potential for Tests 2 and 3 Compared to that for Analytical Model (equation Il).

8. History of Temperature Potential for Test 4 Compared to that for Analytical Model (equation 11).

9. Comparison of Temperature Potential for Test 4 Compared with those of Ideal Water Tanks. 



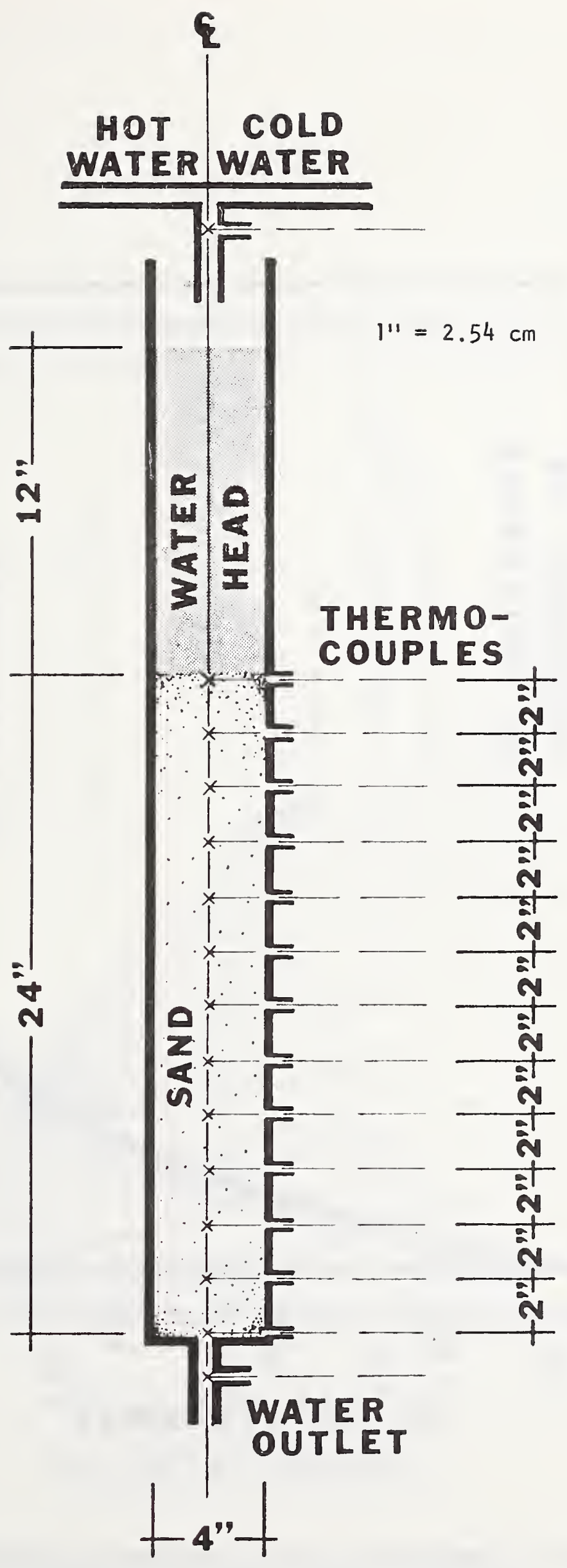

Figure 1. Schematic of Prototype Thermal Storage Unit. 


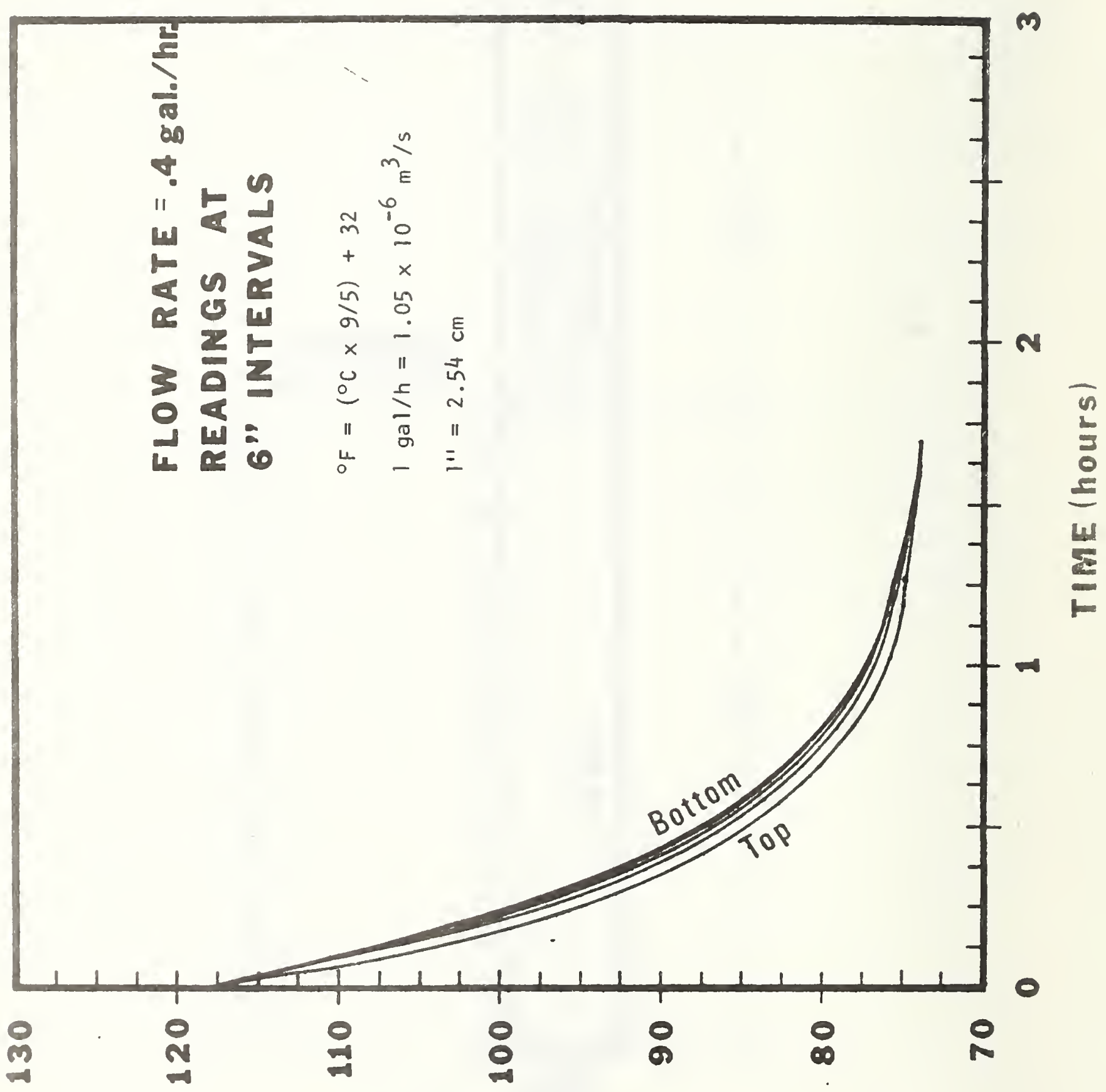

\section{$\left(\unlhd_{0}\right) 3$ dn $1 \forall 43 d W 3 \perp$}

Figure 2. Temperature History of Thermal Storage Unit Initially Filled with Water at $117 \mathrm{~F}$. At Time

Equal Zero, Water at $74 \mathrm{~F}$ and $\mathrm{A}$ Flow Rate of $0.4 \mathrm{gal} / \mathrm{h}$ was Introduced at Top of Unit. 


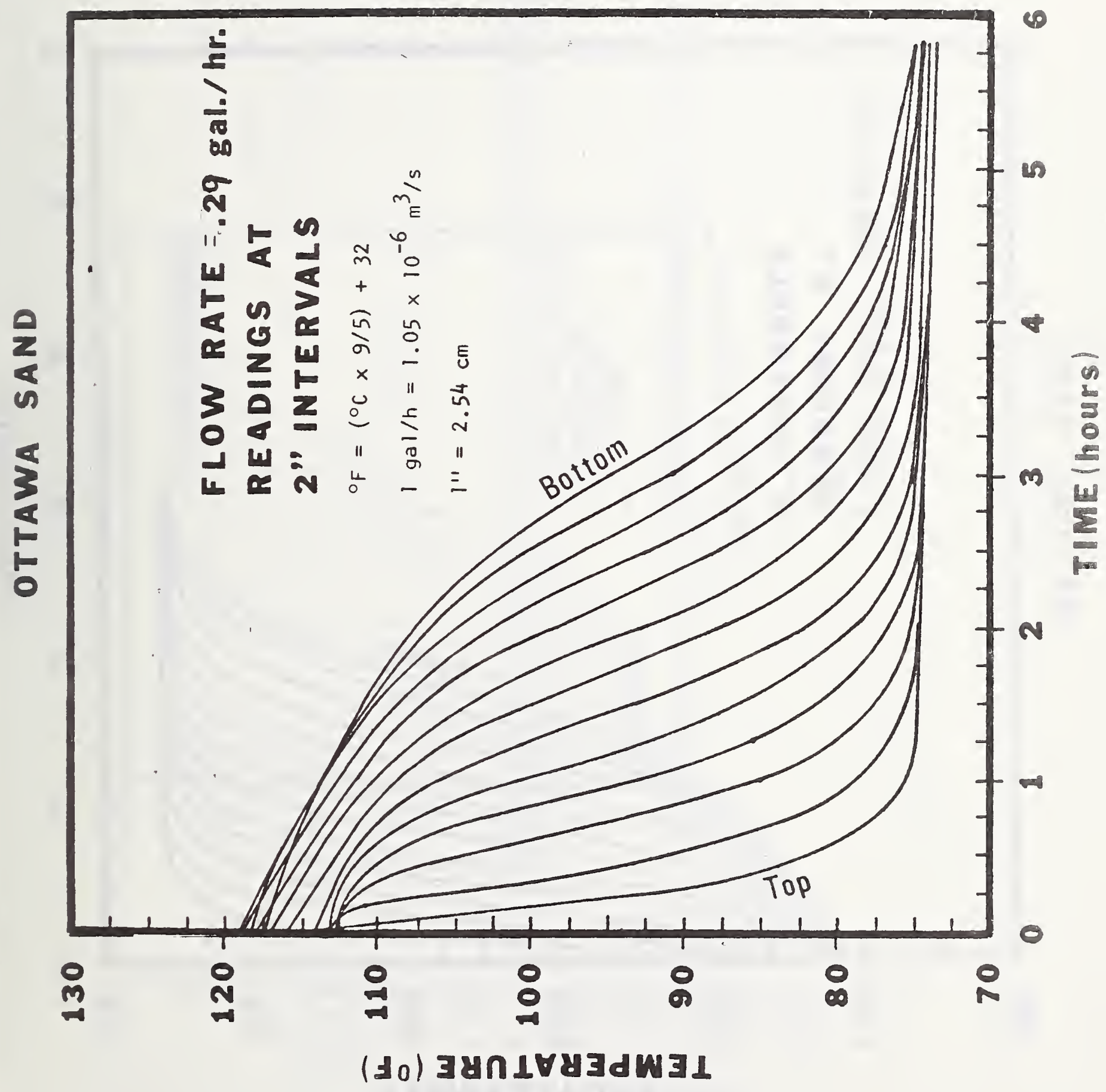

Figure 3. Temperature History of Thermal Storage Unit Filled With a Silica Sand Water Mixture Initially at $116 \mathrm{~F}$. At Time Equal Zero, Water at $74 \mathrm{~F}$ and a Flow Rate of $0.29 \mathrm{ga} 1 / \mathrm{h}$ was Introduced. 


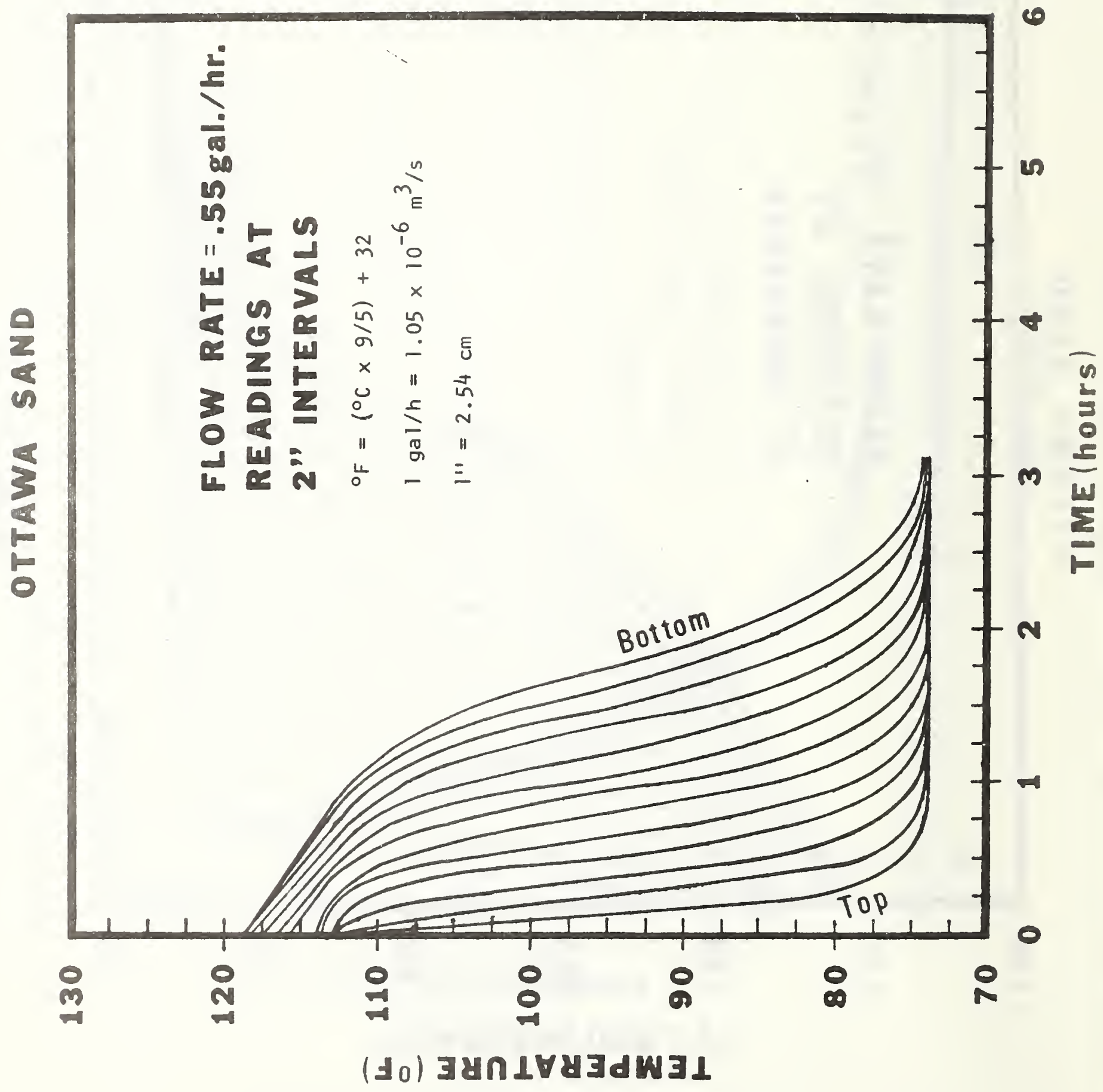

Figure 4. Temperature History for Thermal Storage Unit of Figure 3, Except Flow Rate was. $0.55 \mathrm{gal} / \mathrm{h}$. 


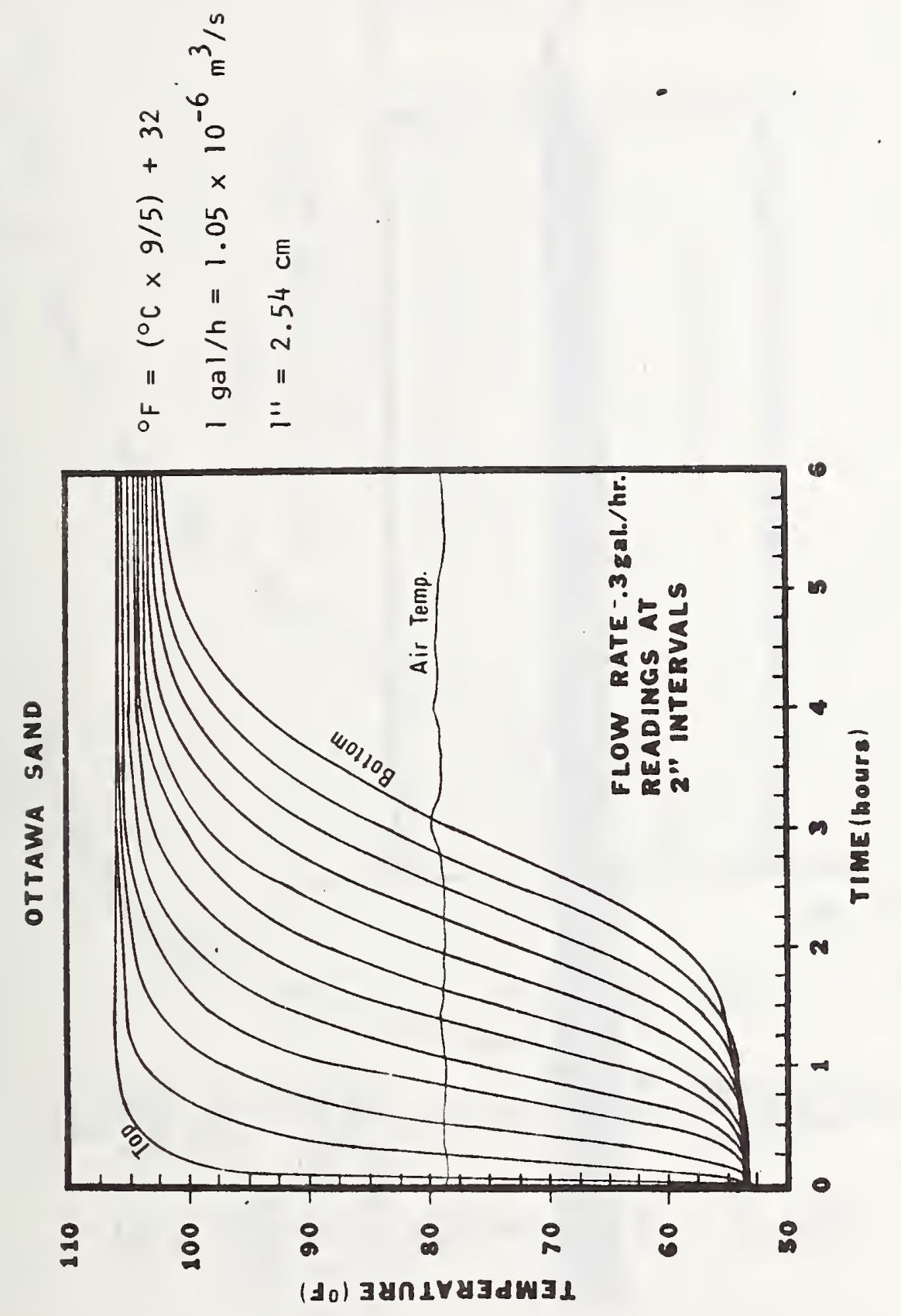

Figure 5. Temperature History of Thermal Storage Unit Initially at 54F. At Time Equal Zero, Water at $106 \mathrm{~F}$ and $\mathrm{A}$ Flow Rate of $0.3 \mathrm{ga} / \mathrm{h}$ was Introduced. 


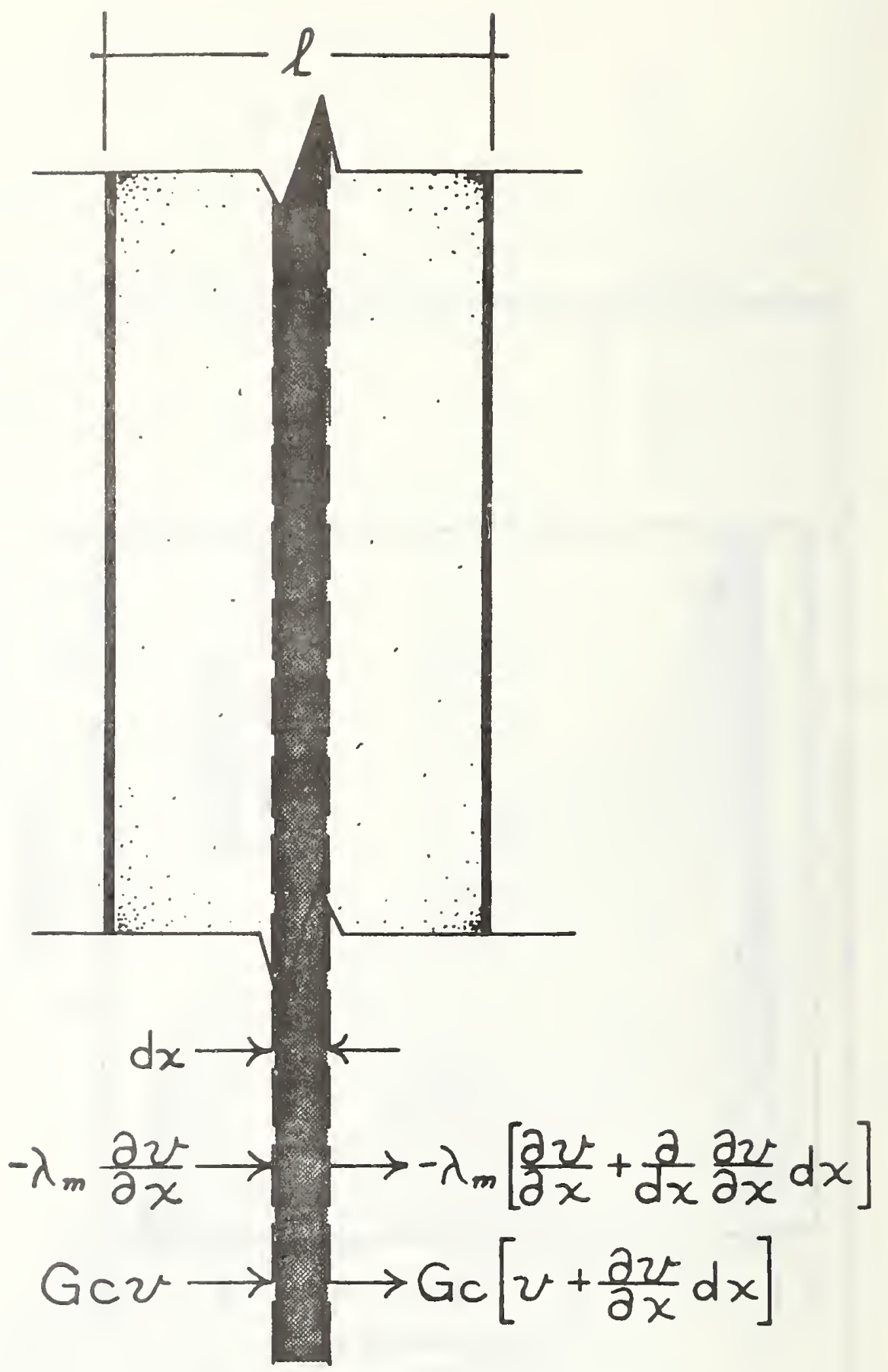

Figure 6. Transpiration Heat Flow Through Flemental slice of Thermal Storage Unit. 


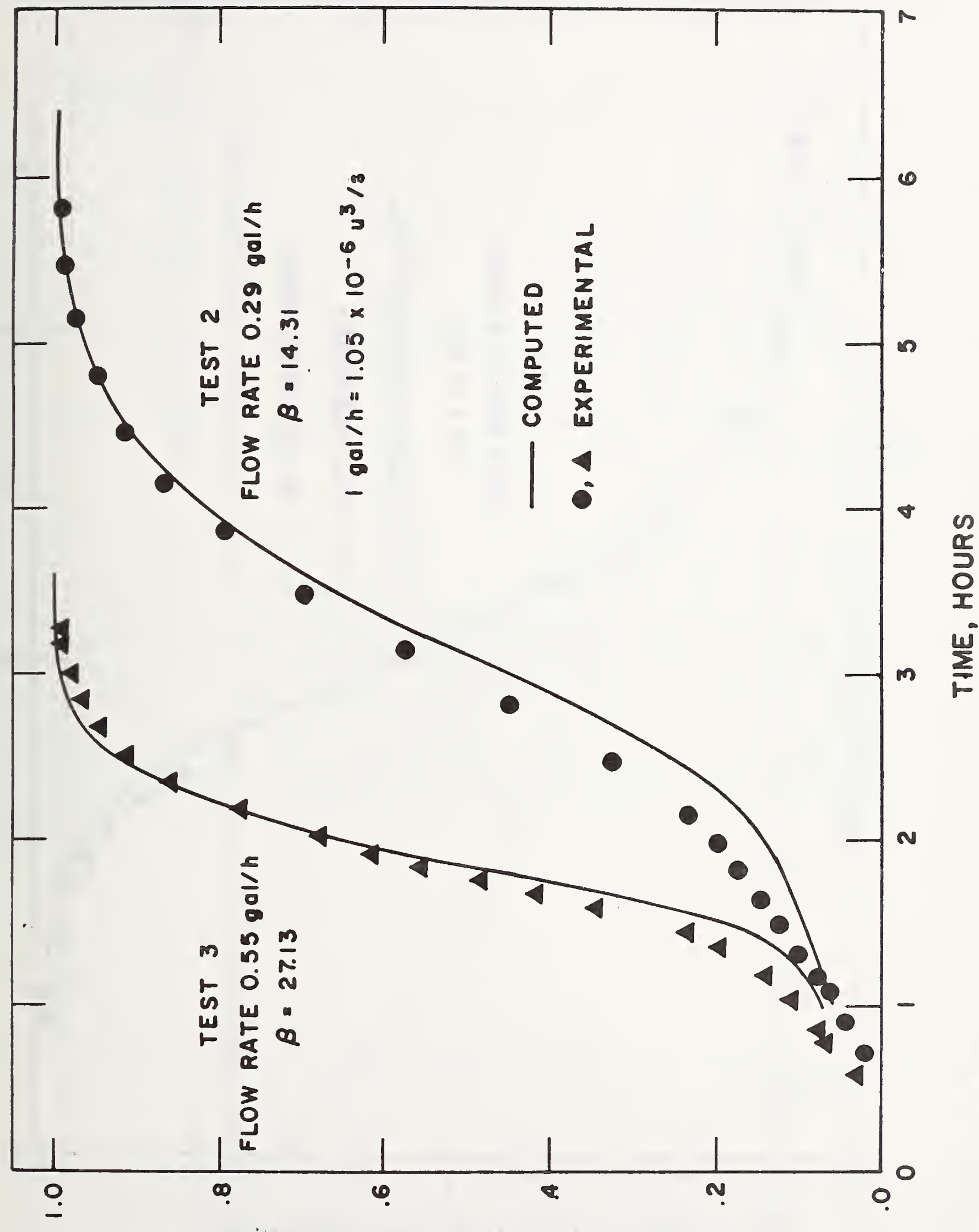

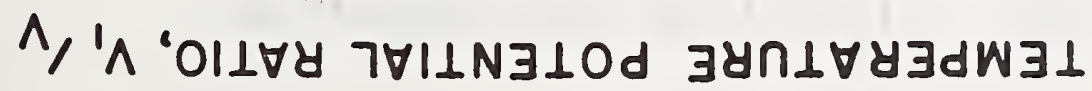

Figure 7. History of Temperature Potential For Tests 2 and 3 Compared To That For Analytical Model (equation 11). 


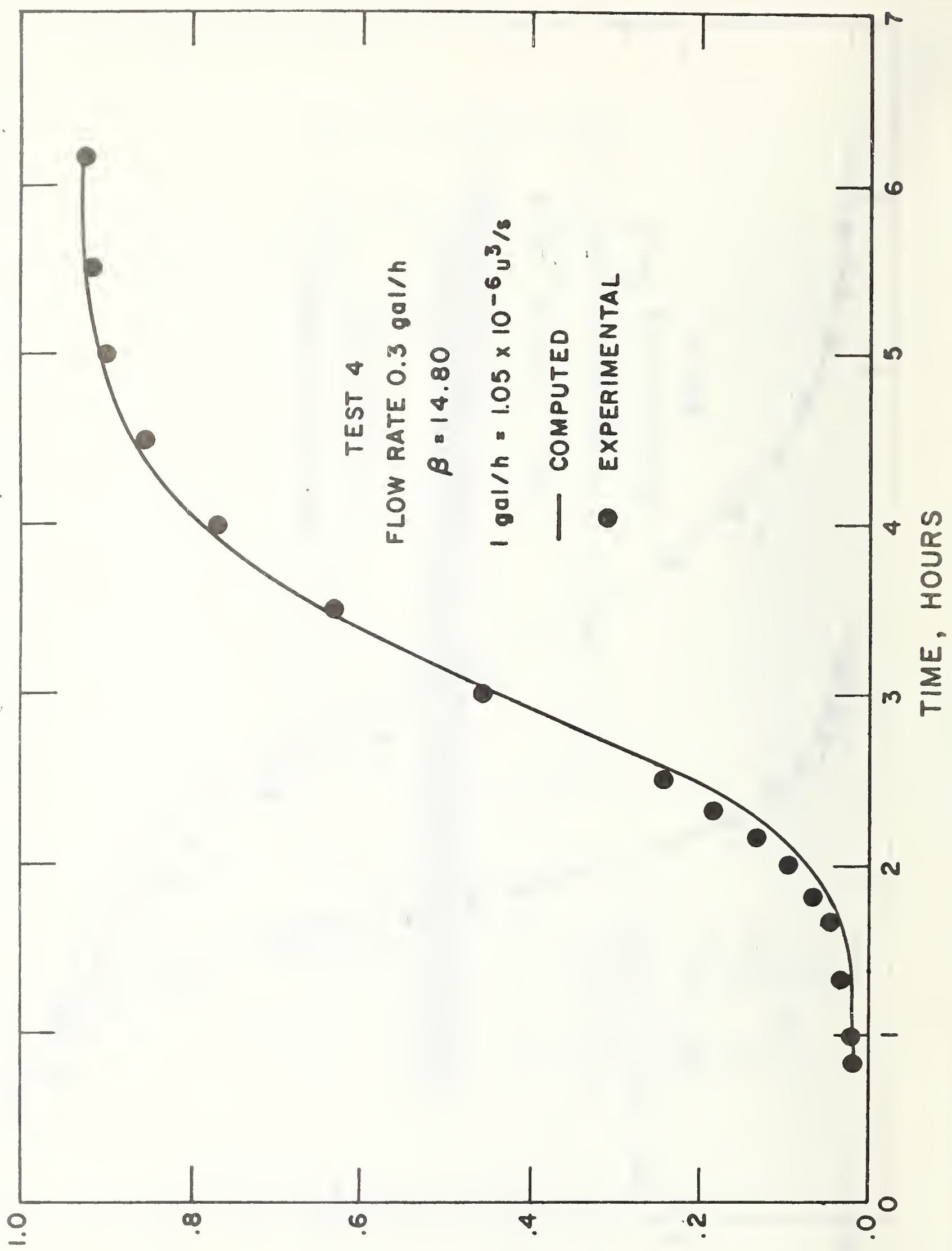

$\wedge / \wedge$ 'OILVY $7 \forall I \perp N \exists \perp$ Od $3 y n \perp \forall y \exists d W \exists \perp$

Figure 8. History of Temperature Potential For Test 4 Compared To That For Analytical Model (equation 11). 


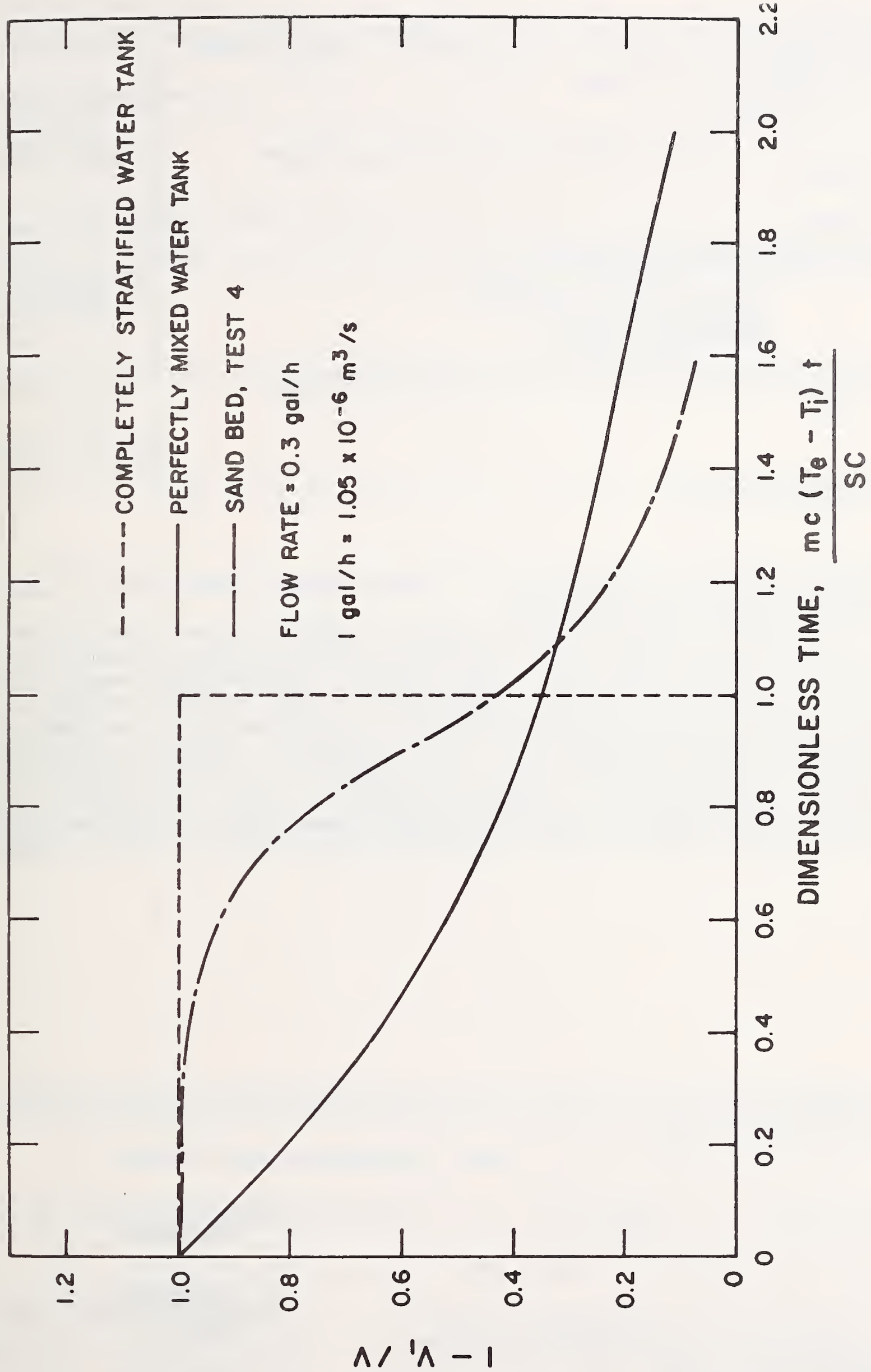

Figure 9. Comparison of Temperature Potential for Test 4 Compared with those of Ideal Water Tanks. 
NBS J14A (REV.7.73)

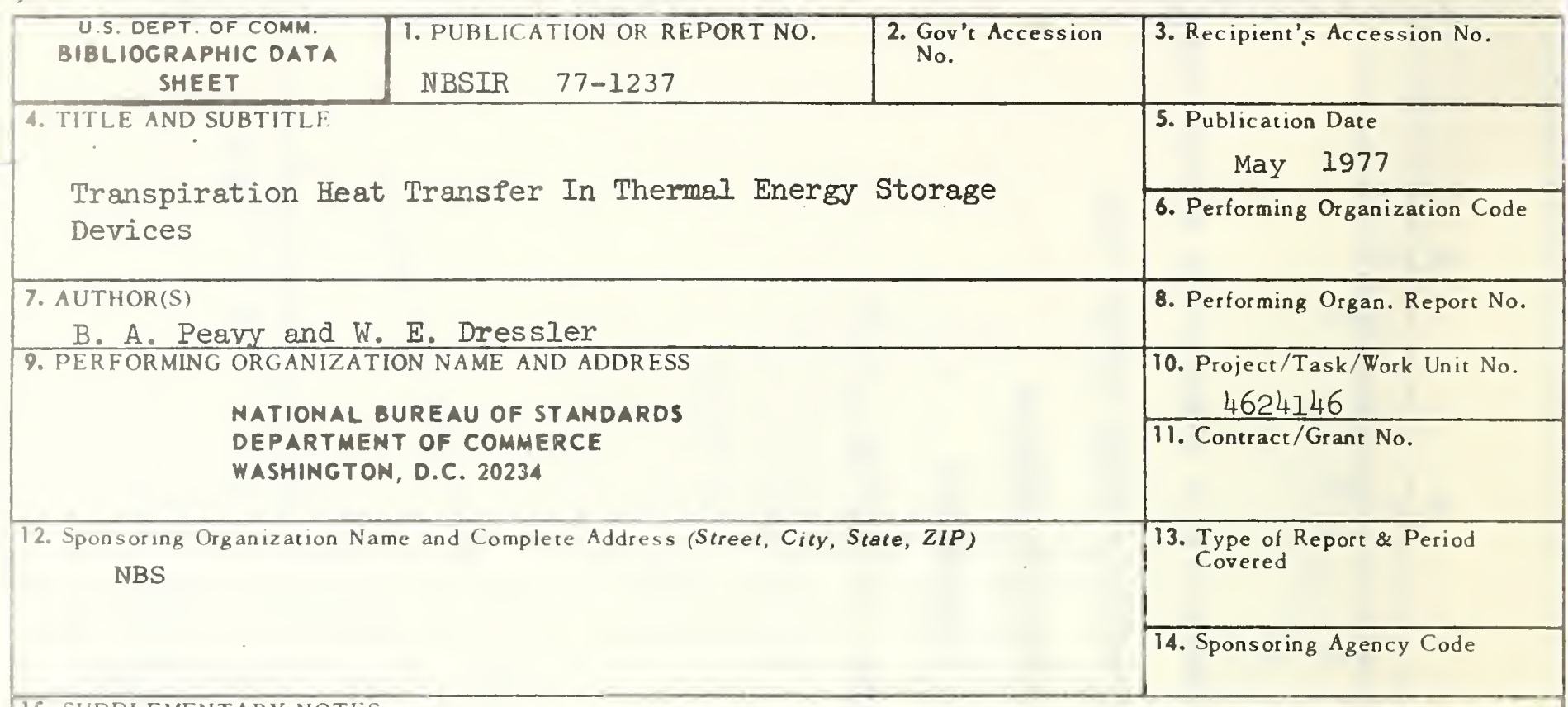

15. SUPPLEMENTARY NOTES

16. ABSTRACT (A 200-word or less factual summary of most significant information. If document includes a significant bibliography or literature survey, mention it here.)

The storage of thermal energy at a suitable temperature level from sources such as solar energy or waste heat processes can make that energy available for space heating at a later time period. This report is concerned with sensible heat transfer that takes place in a thermal storage device composed of a porous material with a fluid (water) transpiring through it. Experiments were performed on a prototype thermal storage device and the results were compared to numerical values computed from an analytical model. The comparison can be considered very good. Further experimentation is considered necessary to define test parameters such as steady initial condition, steady input water temperatures, piston and mixing-type flows, effects of heat losses, and conduction heat flow in the heat storage container.

17. KEY WORDS (six to twelve entries; alphabetical order; capitalize only the first letter of the first key word unless a proper name; separated by semicolons)

Porous media; thermal energy storage; transpiration heat transfer.

18. AVAILABILITY

For Official Distribution. Do Not Release to NTIS

- Order From Sup. of Doc., U.S. Government Printing Office Washington, D.C. 20402, SD Cat. No. C13

Order From National Technical Information Service (NTIS) Springfield, Virginia 22151

\begin{tabular}{|l|c|}
\hline $\begin{array}{l}\text { 19. SECURITY CLASS } \\
\text { (THIS REPURT) }\end{array}$ & $\begin{array}{c}\text { 21. NO. OF PAGES } \\
\text { UNCL ASSIFIED }\end{array}$ \\
\hline $\begin{array}{l}\text { 20. SECURITY CLASS } \\
\text { (THIS P AGE) }\end{array}$ & $\begin{array}{c}\text { 22. Price } \\
\$ 4.00\end{array}$ \\
UNCLASSIFIED & USCOMM.DC 29042-P74 \\
\hline
\end{tabular}



